University of Wollongong

Research Online

Faculty of Social Sciences - Papers (Archive) Faculty of Arts, Social Sciences \& Humanities

1994

Intrusiveness of interventions: ratings by psychologists

R Don Tustin

Minda Incorporated

Barbara Pennington

Minda Incorporated

Mitchell K. Byrne

University of Wollongong, mbyrne@uow.edu.au

Follow this and additional works at: https://ro.uow.edu.au/sspapers

Part of the Education Commons, and the Social and Behavioral Sciences Commons

Research Online is the open access institutional repository for the University of Wollongong. For further information contact the UOW Library: research-pubs@uow.edu.au 


\title{
Intrusiveness of interventions: ratings by psychologists
}

\begin{abstract}
A survey was conducted of opinions of 24 psychologists in South Australia about the intrusiveness of 89 interventions including methods that might be used to reduce challenging behaviour. Interventions arose from a variety of sources, including behavioural psychology and medicine. Interventions might infringe on 8 different rights. Respondents rated the degree to which interventions were perceived to intrude on clients' rights, using a 4-point scale: abusive, very intrusive, intrusive, and not intrusive. A reasonable degree of consistency in ratings was found. Respondents did not rate all interventions that infringed on the same right as being equally intrusive. A number of interventions were rated as being intrusive but not abusive. Intrusive methods may be legitimate if properly authorised. The question arises of how decisions should be made to authorise intrusive methods when clients arc unable to make decisions on their own behalf.
\end{abstract}

\section{Keywords}

psychologists, intrusiveness, interventions, ratings

Disciplines

Education | Social and Behavioral Sciences

\section{Publication Details}

Tustin, R. D., Pennington, B. \& Byrne, M. (1994). Intrusiveness of interventions: ratings by psychologists. Behaviour Change, 11 (2), 94-100. 


\title{
Intrusiveness of Interventions: Ratings by Psychologists
}

\author{
R. Don Tustin and Barbara Pennington \\ Minda Incorporated \\ Mitch Byrne \\ South Australia Department of Correctional Services
}

\begin{abstract}
A survey was conducted of opinions of 24 psychologists in South Australia about the intrusiveness of 89 interventions including methods that might be used to reduce challenging behaviour. Interventions arose from a variety of sources, including behavioural psychology and medicine. Interventions might infringe on 8 different rights. Respondents rated the degree to which interventions were perceived to intrude on clients' rights, using a 4-point scale: abusive, very intrusive, intrusive, and not intrusive. A reasonable degree of consistency in ratings was found. Respondents did not rate all interventions that infringed on the same right as being equally intrusive. A number of interventions were rated as being intrusive but not abusive. Intrusive methods may be legitimate if properly authorised. The question arises of how decisions should be made to authorise intrusive methods when clients are unable to make decisions on their own behalf.
\end{abstract}

The Australian Society for the Study of Intellectual Disability (ASSID) has published a booklet discussing ethical and legal principles that arise when interventions infringe the human rights of clients (Anderson, 1993). An intervention that infringes or restricts rights is said to be intrusive. The use of an intrusive intervention might be justified if it reduces challenging behaviour. However, questions arise both of how to identify intrusive interventions, and how to authorise the use of an intrusive intervention, especially if clients are unable to make decisions on their own behalf. In Australian law, the use of intrusive methods is legitimate only if authorised using a legally recognised decisionmaking process (Hayes \& Hayes, 1982).

Discussion about methods to reduce challenging behaviour has continued since behavioural psychologists first reported effective methods arising from the principles of learning (Foxx, 1982). Subsequent writers have noted that, once the effectiveness of an intervention is established, questions of social acceptability become important (Butterfield, 1990; Gerhardt, Holmes,
Alessandri, \& Goodman, 1991; Lennox \& Miltenberger, 1990).

Special concern has been expressed about aversive interventions (Guess, Helmstetter, Turnbull \& Knowlton, 1987). From a social perspective, an intervention is aversive if it produces objective signs of discomfort such as pain reactions, tissue damage, physical illness, severe physical or emotional stress, or conditions that require medical treatment (Association for Persons with Severe Handicaps, 1986). Several writers argue that aversive intervention should not be used with clients who are dependent on carers, are vulnerable to abuse, and are unable to make decisions about interventions (Harris \& Handleman, 1990; Horner, 1990; La Vigna \& Donnellan, 1986; Repp \& Singh, 1990).

In addition to the concern about aversive interventions, Australian lawyers have expressed concern about interventions that infringe any human right of a client (Cootes, Simpson \& West, 1988; Hayes \& Hayes, 1982; O’Sullivan, 1983; Simpson, 1987). Under Australian law, any person who infringes a 
right of another person without proper consent is liable to legal action.

Cootes et al. (1988), in a book cosponsored by the Law Foundation of NSW, provided a basis for identifying intrusive interventions. They identified 8 rights that might be infringed by carers using programs aimed at reducing challenging behaviour. Proposed rights involved: Bodily integrity or the right to be free from unwanted touch and stimulation; being treated with Respect by carers; freedom of Movement; being free to Socialise with peers and friends; having free Choice of activities; having free access to personal Property; having the Privacy of personal information respected; and being free of Medication and drugs.

There has been considerable discussion about interventions involving touch. Some lawyers view any unconsenting touch as being assault because it infringes a right to bodily integrity (Cootes et al., 1988; Hayes \& Hayes, 1982; Simpson, 1987). On the other hand, psychological research shows that touch plays an important role in nonverbal communication, and has a positive influence in forming interpersonal relations (Thayer, 1988). Touch can communicate messages of support, encouragement, appreciation, affection, caring, and reassurance. Further, therapists from diverse theoretical backgrounds have defined specific types of touch as being therapeutic if used appropriately. Touch has been shown to calm people who are distressed (Triplett \& Arneson, 1979), to provide alternative sensory input for people with severe behaviour disturbances (Jones, 1980), to prompt people to use skills (Foxx, 1982), to assist sensory integration (Ayres, 1972), and to replace maladaptive patterns of behaviour with more appropriate behaviour (Doman, 1974).

Concern about intrusive interventions has not been restricted to those interventions arising from the principles of behavioural psychology. Lawyers express concern about intrusive practices arising from any source, including from medical practitioners who recommend drugs, from physical therapists who recommend equipment such as splints and helmets, and from institutional practices. This produces a need to assess the intrusiveness of interventions independently both of the source of the intervention, and of the reason for using the intervention.

In Australian law, use of an intrusive intervention is legitimate only if it has been approved by a person authorised to give legal consent on behalf of the client. This decision maker resolves whether the proposed intervention is justifiable in the circumstances of the case.

Parents may wish only to be informed about decisions involving discipline of their children, rather than be asked to make decisions themselves (Lusthaus, Lusthaus, \& Gibbs, 1981). This leaves unresolved the question of who should authorise the use of intrusive interventions so as to safeguard both clients and therapists.

The ASSID document proposes that different decision-making practices be used to authorise behaviour management programs, depending on the intrusiveness of the intervention. It was recommended that all formal behaviour management programs be recommended by qualified professionals. A decision to implement a formal program would be made either by the client, or by the client's parents or advocate, or by a relevant service manager. If a program involves very intrusive methods, then a decision to implement the program might be made by a legal body, such as a guardianship board or a delegated guardian.

Psychologists have previously examined the acceptability of interventions using two approaches, namely ratings of social acceptability (Blampied \& Kahan, 1992; Singh, Watson \& Winton, 1987), and hierarchies of restrictiveness (Morgan, 1989). However, as neither approach deals directly with the issue of infringement on human rights, neither approach distinguishes intrusive from nonintrusive interventions.

Ratings of the social acceptability of interventions are obtained by asking respondents to rate the acceptability of an intervention for reducing a specific problem behaviour (Kazdin, 1980a). Respondents are asked to balance the intrusiveness of an intervention against the severity of a behaviour, rather than to judge the intrusiveness of the intervention.

Morgan (1989) provided a critical review of hierarchies of restrictiveness of interventions provided by 5 individual experts. Morgan found differences of opinion between the experts, with experts being unable to agree even on the number of categories required to describe levels of restrictiveness. There was criticism of the approach of using individual opinions instead of the collective judgment of members of a professional group.

The intrusiveness of interventions might be assessed using a scale where respondents rate the degree to which an intervention infringes on a human right. No studies using this approach were found. 
The present study aimed to identify the opinions of a group of psychologists about the intrusiveness of a wide range of interventions. The opinions of psychologists or clinical psychologists about intrusiveness are relevant as: (a) some interventions were introduced by psychologists, (b) psychologists are asked to recommend methods for managing challenging behaviour, and (c) psychologists are asked to comment on interventions proposed by others.

Interventions were included that were expected to be rated on each point of a continuum from being abusive to being nonintrusive. Some interventions were included as markers because they are widely considered to be abusive and are not part of any therapy.

\section{METHOD}

A questionnaire was sent to 32 senior psychologists in South Australia, under the sponsorship of the South Australian branch of the Australian Behaviour Modification Association. Responses were received from 24 respondents, giving a response rate of $75 \%$

Respondents were asked about the clients they worked with, the reasons why clients were referred to them, and how frequently respondents used behavioural interventions.

The percentages of respondents who reported working with each category of clients were:

- $83 \%$ worked with adults

- $67 \%$ with families

- $63 \%$ with high school children

- $42 \%$ with primary school children

- $38 \%$ with pre-school children

The percentages of reasons why clients were referred to psychologists were:

- $63 \%$ for behaviour problems

- $50 \%$ for mental health problems

- $42 \%$ for skill development

- $33 \%$ for problems associated with developmental disability.

The percentages of respondents who reported using behavioural interventions were:

- $45 \%$ "frequently or often"

- $42 \%$ "sometimes"

- 13\% "rarely or never".

A definition of intrusiveness given on the questionnaire emphasised human rights: "An intervention is intrusive if it limits or restricts what is normally considered a right". A statement was made that rights may be restricted only if adequate reasons are provided in a legitimate decision-making process.
Respondents rated the degree of intrusiveness of each intervention using a 4-point scale: not intrusive (1), intrusive (2), very intrusive (3), and abusive (4).

It is assumed that abusive methods are never legitimate. Intrusive methods may be legitimate if they are authorised using proper decision-making procedures. Nonintrusive methods do not require extraordinary decisionmaking procedures.

Respondents were asked to rate the degree of intrusiveness of each of 89 interventions, which were described by labels and definitions. Labels for interventions are given in Table 1 . Definitions are available from the authors. Some illustrative definitions follow. Touch reinforcer was defined, "A carer briefly and gently touches a client on a public part of the body (e.g., a hand or shoulder) either to show affection or to reinforce behaviour". Isolation timeout was defined, "Following a defined misbehaviour, a client is confined alone into a locked room for a brief period of about 15 minutes, and remains until the behaviour has stopped". Exclusionary timeout was defined, "Following defined misbehaviour, a client is removed from a reinforcing environment for a specified period of time, but is not placed into a secure area". Teasing was defined, "Someone continually says something to a client which has the primary effect of annoying the person, rather than teaching the person to behave more appropriately". Restricting access to meals was defined, "A procedure where carers refuse access to meals at usual mealtimes following misbehaviour such as disrupting a dining room or leaving a dining room".

Interventions were grouped in the questionnaire according to the human right involved, using the categories suggested by Cootes et al. (1988). The numbers of interventions associated with each right were: 32 with Bodily integrity, 26 with Respect by carers, 8 with Movement, 7 with Socialisation, 6 with Choice of activity, 5 with Property, 3 with Privacy of information, and 2 with Medication. The classification of each intervention is shown in Table 1.

\section{RESULTS}

Three measures were used to summarise ratings by respondents: (a) modal rating or rating given by most respondents, (b) mean rating, and (c) per cent of respondents who rated an intervention as being contentious (rating between 2 and 4). Table 1 shows these measures for each intervention. 
TABLE 1 Interventions Ranked by Modal Rating, with Mean Rating, Per Cent of Respondents who Considered the Method Contentious, and Right Infringed

INTERVENTION MODE MEAN PER CENT CONTENTIOUS RIGHT

\section{Abusive}

Corporal punishment

Strike

Sexual touch

Ridicule

Painful stimuli

Tease

\section{Very intrusive}

Intrude on privacy

Restrict communication

Restrict family contact

Prohibit contact

Sensory irritant

Restrictive clothing

Preventive restraint

Confine

Custodial care

Secure area

Mechanical restraint

Water mist

Physical restraint

Peer retaliation

Bodily restraint

Smack

Flooding

Isolation time out

Detain

Unpleasant stimuli

Forfeit property

\section{Intrusive}

Punish

Visual screening

Negative peer pressure

Flannel

Public reprimand

Restrict meal access

Medication

Enter personal space

Push

Sensory extinction

Contingent restraint

Interrupt sleep

Response interruption

Negative practice

Stigmatising equipment

Group contingency

Forced exercise

Token program

Peer assertion

Over correction

PRN medication

Restrict peer contact

Semisecure area

Response cost

Restrict movement

Suspension

Emotional reprimand

Manual restraint

Lift person

Group program

Structured program

Required relaxation

Physical correction

Separation

Exclusionary time-out
3.92

3.75

3.70

3.57

3.54

3.45

3.39

3.04

3.00

2.96

2.92

2.87

2.86

2.83

2.79

2.70

2.63

2.61

2.58

2.56

2.54

2.54

2.50

2.48

2.46

2.43

2.33

2.41

2.35

2.33

2.30

2.30

2.29

2.25

2.25

2.21

2.13

2.09

2.09

2.08

2.04

2.00

1.96

1.96

1.96

1.96

1.92

1.92

1.91

1.91

1.88

1.88

1.88

1.86

1.83

1.83

1.79

1.75

1.71

1.71

1.67

1.65
100

100

100

100

100

100

100

100

100

100

100

85

96

96

92

100

92

91

96

92

92

92

87

100

96

76

83

95

91

87

87

87

91

83

96

91

87

83

83

83

73

70

80

75

75

70

83

62

83

70

75

70

58

68

75

65

56
Bodily integrity

Bodily integrity

Bodily integrity

Respect

Bodily integrity

Respect

Privacy

Socialise

Socialise

Socialise

Bodily integrity

Bodily integrity

Bodily integrity

Movement

Movement

Movement

Bodily integrity

Bodily integrity

Bodily integrity

Socialise

Bodily integrity

Bodily integrity

Respect

Movement

Movement

Bodily integrity

Property

Bodily integrity Bodily integrity Respect

Bodily integrity

Privacy

Choice

Medication

Bodily integrity

Bodily integrity

Bodily integrity

Bodily integrity

Choice

Bodily integrity

Respect

Respect

Privacy

Bodily integrity

Property

Respect

Respect

Medication

Socialise

Movement

Property

Movement

Choice

Respect

Bodily integrity

Bodily integrity

Respect

Choice

Respect

Bodily integrity

Socialise

Movement 
TABLE 1 Continued

\begin{tabular}{|c|c|c|c|c|}
\hline INTERVENTION & MODE & MEAN & PER CENT CONTENTIOUS & RIGHT \\
\hline \multicolumn{5}{|l|}{ Intrusive cont'd } \\
\hline Satiation & 2 & 1.57 & 53 & Respect \\
\hline Massage & 2 & 1.57 & 52 & Bodily integrity \\
\hline Nonexclusionary time out & 2 & 1.52 & 52 & Respect \\
\hline Positive practice & 2 & 1.50 & 50 & Respect \\
\hline \multicolumn{5}{|l|}{ Nonintrusive } \\
\hline Monetary compensation & 1 & 1.52 & 44 & Property \\
\hline Posture & 1 & 1.50 & 41 & Respect \\
\hline Covert sensitisation & 1 & 1.48 & 43 & Respect \\
\hline Physical guidance & 1 & 1.46 & 46 & Bodily integrity \\
\hline Desensitisation & 1 & 1.46 & 37 & Respect \\
\hline Reflect feelings & 1 & 1.46 & 29 & Socialise \\
\hline Structured day & 1 & 1.42 & 37 & Choice \\
\hline Ignore behaviour & 1 & 1.39 & 39 & Respect \\
\hline Calming touch & 1 & 1.35 & 35 & Bodily integrity \\
\hline Physical prompt & 1 & 1.30 & 30 & Bodily integrity \\
\hline Self defence & 1 & 1.30 & 29 & Bodily integrity \\
\hline Joke with person & 1 & 1.26 & 21 & Respect \\
\hline House rules & 1 & 1.25 & 25 & Choice \\
\hline Restitution & 1 & 1.25 & 25 & Property \\
\hline Gesture & 1 & 1.25 & 21 & Respect \\
\hline Tactile stimulation & 1 & 1.23 & 23 & Bodily integrity \\
\hline Touch reinforcer & 1 & 1.22 & 23 & Bodily integrity \\
\hline Reprimand & 1 & 1.22 & 23 & Respect \\
\hline Firm calm reprimand & 1 & 1.22 & 17 & Respect \\
\hline Authoritative manner & 1 & 1.17 & 17 & Respect \\
\hline Correction & 1 & 1.08 & 9 & Respect \\
\hline Divert & 1 & 1.08 & 9 & Respect \\
\hline Discrimination training & 1 & 1.08 & 9 & Respect \\
\hline
\end{tabular}

Interventions were classified into 4 categories according to modal ratings. Six interventions were classified as being Abusive, 21 interventions as being Very intrusive, 39 interventions as being Intrusive and 23 interventions as being Nonintrusive. Classifications of interventions are shown in Table 1.

Interventions classified as abusive had mean ratings over 3.40 and were considered contentious by all respondents. Interventions classified as very intrusive had mean ratings between 2.33 and 3.40 , and were considered contentious by between $76 \%$ and $100 \%$ of respondents. Interventions classified as intrusive had mean ratings between 1.50 and 2.45 , and were considered contentious by between $50 \%$ and $96 \%$ of respondents. Interventions classified as nonintrusive had mean ratings between 1.08 and 1.52 , and were considered contentious by between $9 \%$ and $46 \%$ of respondents. By these criteria, interventions are given similar classifications using modal or mean measures.

Relations between rated degree of intrusiveness and right infringed are shown in Table 2. Of the 6 interventions considered abusive, 4 involved bodily integrity and 2 involved respect by carers. Of the 21 interventions considered very intrusive, 9 involved bodily integrity, 5 involved movement, 4 involved socialising, and 1 each involved respect, property, and privacy. Of the 39 intrusive interventions, 13 involved bodily integrity, 11 involved respect from carers, 4 involved choice, 3 involved movement, and 2 each involved socialising, property, privacy, and medication. Of the 23 nonintrusive interventions, 12 involved respect, 6 involved bodily integrity, 2 involved choice and property, and 1 involved socialisation.

Infringements on 3 rights were always considered contentious. These rights involved movement, privacy, and taking medication.

No strong relation was found between specific right infringed and degree of intrusiveness. Of the 32 interventions associated with bodily integrity, $13 \%$ were rated as being abusive, $28 \%$ as being very intrusive, $40 \%$ as being intrusive, and $19 \%$ as being nonintrusive. Similarly with interventions associated with the right to be treated with respect by carers; $8 \%$ of interventions were rated as being abusive, $42 \%$ as being intrusive, and $46 \%$ as being nonintrusive. Infringements on these rights were rated across the full range of intrusiveness from being abusive to being nonintrusive. 
The study identified 60 interventions as being intrusive but possibly legitimate.

\section{DISCUSSION}

Psychologists were asked individually to rate the degree to which 89 interventions infringe on human rights. Interventions were selected to give examples arising from several sources, including behavioural psychology, medicine, and other sources. Interventions were selected that were likely to fall along a continuum from being abusive to being nonintrusive.

Ratings were summarised using 3 measures. Classifications of degrees of intrusiveness of interventions were similar, using the alternative measures.

The study did not find a strong association between degree of intrusiveness and specific rights infringed. Some interventions that infringed all of the 8 rights were considered to be contentious. At the same time, other interventions that infringed the same rights were rated as nonintrusive. Interventions rated as nonintrusive included some infringements on bodily integrity (physical guidance, calming touch), on property (restitution, monetary compensation), on choice (structured day, house rules), and on respect (reprimanding, using an authoritative manner).

Findings can be compared to opinions expressed by legal commentators. Respondents in this study rated some but not all interventions that infringe on bodily integrity as being abusive. Four types of touch were considered abusive. At the same time, some interventions involving touch were rated as being intrusive, but not abusive. As noted above, a number of interventions involving touch were not considered intrusive, including physical guidance, calming touch, and touch reinforcers.

Some legal commentators have described any intervention that restricts freedom of movement as being false imprisonment (Cootes et al., 1988). In the present study, interventions that restrict freedom of movement were rated as being intrusive, but not abusive. Isolation time-out was rated as being very intrusive, while exclusionary timeout was rated as being intrusive.

The results of the survey can also be compared with opinions expressed in the ASSID document. The present study agreed with the ASSID document that certain interventions are unacceptable. Methods classified as unacceptable by ASSID and as abusive in this study are inflicting painful stimuli, corporal punishment, striking a client, and teasing a client.

The ASSID document identified some methods as being unacceptable, while the criteria applied in the present study classified the methods only as being very intrusive. Such methods included isolation time-out, using mechanical restraint, and restricting access to meals.

The results of the present study can also be compared to studies of social acceptability: Isolation time-out was rated as more intrusive than exclusionary time-out, agreeing with Kazdin (1980a). Painful stimulation was rated as more intrusive than medication, which in turn was rated as more intrusive than discrimination training, consistent with the findings of Kazdin (1980b). Time-out and medication were rated as more intrusive than overcorrection and discrimination training, consistent with the findings of Singh et al. (1987). Medication was rated as

TABLE 2 Numbers of Interventions Rated at Each Level of Intrusiveness, Separated by Rights

\begin{tabular}{lccccc} 
& \multicolumn{2}{c}{ RATED DEGREE OF INTRUSIVENESS } \\
RIGHT & Abusive & Very Intrusive & Intrusive & Not Intrusive & Sum \\
\hline Bodily integrity & 4 & 9 & 13 & 6 & 32 \\
Respect & 2 & 1 & 11 & 12 & 26 \\
Movement & 0 & 5 & 3 & 0 & 8 \\
Socialise & 0 & 4 & 2 & 1 & 7 \\
Choice & 0 & 0 & 4 & 2 & 6 \\
Property & 0 & 1 & 2 & 2 & 5 \\
Privacy & 0 & 1 & 2 & 0 & 3 \\
Medication & 0 & 0 & 39 & 23 & 89 \\
\hline Totals & 6 & 21 & & & \\
\hline
\end{tabular}


more intrusive than exclusionary time-out, as was found by Kazdin (1984).

The study represents a step towards establishing normative views of psychologists in Australia about the intrusiveness of a range of interventions. As the study involved a comparatively small group, replication studies are important. Surveys of opinions of people from different professional backgrounds will show whether psychologists have similar views to other groups.

The study identified several interventions rated by psychologists as being intrusive but legitimate if properly authorised. Commentators emphasise the need to obtain formal consent before using intrusive interventions. To achieve this, it will be necessary to clarify decision-making procedures that are suitable for authorising the use of intrusive interventions. In time, information will become available about grounds that have been widely accepted as justifying the use of intrusive interventions.

\section{REFERENCES}

Anderson, M. (1993). Behaviour management: An approach for the $90 \mathrm{~s}$. Newcastle, NSW: Australian Society for the Scientific Study of Intellectual Disability, University of Newcastle.

Association for Persons with Severe Handicaps, (1986). Resolution on the cessation of intrusive interventions. In L.H. Meyer, C.A. Peck, \& L. Brown (Eds.) Critical issues in the lives of people with serere disahilities, $\mathrm{p}$. 550. Baltimore, MA: Paul Brookes.

Ayres, J.A. (1972). Sensory integration and learning disorders. LA: Western Psychological Services.

Blampied, N.M., \& Kahan, E. (1992). Acceptability of alternative punishments. Behaviour Modification, 16. $400-413$.

Butterfield, W. (1990). The compassion of distinguishing punishing behavioral treatment from aversive treatment. American Journal on Mental Retardation, 95, 137-141

Cootes J., Simpson, J., \& West, R. (1988). Rights in residences. Sydney: Southwood Press.

Doman, G. (1974). What to do with your brain-injured child. London: Cape

Foxx, R.M. (1982). Decreasing behaviors of severely retarded and autistic persons. Champaign, IL: Research.

Gerhardt, P., Holmes, D.L., Alessandri, M., \& Goodman, M. (199I). Social policy on the use of aversive interventions: Empirical, ethical, and legal considerations. Journal of Autism and Developmental Disorders, 21 , 265-280.

Guess, D., Helmstetter, E., Turnbull, H.R., \& Knowlton, S. (1987). Use of aversive procedures with people who are disabied: A historical review and critical analysis. Journal of the Association for Persons with Severe Handicaps, 2, 1-68.

Harris, S., \& Handleman, J. (1990). Aversive and nonaversive interventions: Controlling life-threatening behaviour in the developmentally disabled. New York: Springer-Verlag.

Hayes, S.C., \& Hayes, R. (1982). Mental retardation: Law, policy and administration. Sydney: Law Book Company.

Horner, R. (1990). Ideology, technology, and typical community settings: Use of severe aversive stimuli. American Journal on Mental Retardation, 95, 166-168.

Jones, C. (1980). The uses of mechanical vibration with the severely mentally handicapped: Part $2 \ldots$ behavioura! effects. Apex, Journal of the British Institute of Mental Handicap, 7, 112-114.

Kazdin, A.E. (1980a). Aceeptability of alternative treatments for deviant child behaviour. Journal of Applied Behaviour Analysis, 13, 259273.

Kazdin, A.E. (1980b). Acceplability of timeout from reinforement procedures for disruptive child behaviour. Behaviour Therapy, 11, $329 \cdot 344$.

Kazdin, A.E. (1984). Acceptability of aversive procedures and medication as treatment alternatives for deviant child behaviour. Journal of Abnormal Child Psychology, 12, 289-302.

La Vigna, G., \& Donnellan, A. (1986). Alternatives to punishment: Solving behaviour problems with non-aversive strategies. New York: Irvington.

Lennox, D.B., \& Miltenberger, R.G. (1990). On the conceptualization of treatment acceptability. Education and Training in Mental Retardation, 25, $211-224$.

Lusthaus, C.S., Lusthaus, E.W.. \& Gibbs, H. (1981). Parents' role in the decision process. Exceptional Children, 48, 256-257.

Morgan, R.L. (1989). Judgments of restrictiveness, social acceptability, and usage: Review of research on procedures to decrease behaviour. American Journal on Mental Retardation, 94, 12!-133.

O'Sullivan, J. (1983). Law for nurses and allied health professionals in Australia. Sydney: Law Book Company.

Repp, A., \& Singh, N. (1990). Perspectives on the use of nonaversive and aversive interventions for persons with developmental disabilities. Sycamore, IL: Sycamore.

Simpson, J. (1987). Behaviour management versus rights. Interaction, $1,9-10$.

Singh, N.N., Watson, J.E., \& Winton, A.S.W. (1987). Parents' acceptability ratings of alternative treatments for use with mentally retarded children. Behaviour Modification, $1 /, 17-26$.

Thayer, S. (1988). The language of touch. In P. Marsh (Ed.), Eye to eye: How people interact (pp. 88 97). Oxford: Andromeda.

Triplett, J.L.. \& Arneson, S.W. (1979). The use of verbal and tactile comfort to alleviate distress in young hospitalized children. Research in Nursing and Health, 2, $17 \cdots 23$. 